Review of Darwinism and economics, edited by Geoffrey M. Hodgson (The International Library of Critical Writings in Economics Series, vol. 233). Cheltenham and Northampton: Edward Elgar, 2009, 457 pp.

\title{
VALENTIN COJANU
}

Bucharest Academy of Economic Studies

The reorienting of economics has by now gained full momentum, although one can still barely see how its different themes are converging. The Critical Writings in Economics collection provides a window into the course of this hard to follow trend thanks to its auspicious combination of a publisher's committed interest, the patronage of Mark Blaug as series editor, and exemplary paper anthologies. Volume 233 comes out of the efforts of Geoffrey M. Hodgson, a leading thinker in the institutional and evolutionary current in economics and an authoritative advocate of the historical specificity of economics. It consists of a selection of 24 contributions previously published between 1990 and 2008 that build the case for understanding economic behaviour as ultimately a reflection of evolutionary principles.

The schema the editor proposes for reading this selection is based on a dichotomy between theories of interaction and of communality, to reflect causal interaction between the natural and the social world, and concepts and assumptions shared by both domains, respectively. In spite of overlapping themes, mostly resulting from the underlying genotype-phenotype distinction that may render that dichotomy redundant, the book's schema forcefully points to the influences currently feeding into economics across established disciplinary boundaries, from biology, genetics, history, anthropology, psychology, and management theory. 'Imperialist economics' is apparently no more; the dominant feeling now is an inferiority complex.

John Nightingale ("Universal Darwinism and social research", 2000) reminds us about the admittedly pejorative picture of the economist as a "scavenger digging around the mullock heaps of the more developed sciences, searching for scraps of sustenance". The same feeling is evoked by Jack J. Vromen ("The human agent in evolutionary economics", 2001), when he voices the concern that one serious 
shortcoming of mainstream economics is that "it simply ignores insights and ideas developed in adjacent disciplines".

Two of the three parts of the volume are engaged in explaining how evolutionary theory changes the basic economic tenets of rationality and causality. Part one takes on the former and expounds the biological shaping of individual decision-making at the level of individual and group selection, preferences and beliefs. Equating selection with market competition bears the mark of "the banality of mathematics and logic applied to survivability" leading to a "deducible theorem of "competitive exclusion'”, advises Paul Samuelson ("The economics of altruism”, 1993). The mind's development engenders all economic behaviour by fitting together the parts of a decision-making machinery, such as computational brain modules that adapt themselves to the simultaneous needs of "reasoning instincts" to express intentionality (Leda Cosmides and John Tooby, "Evolutionary psychology and the invisible hand", 1994); "informational inputs" to account for cultural diversity (Jack J. Vromen); or maladaptive traits such as altruistic behaviour for the survival value they confer on populations (Herbert A. Simon, "A mechanism for social selection and successful altruism”, 1990).

Facing a domain that has long left behind its pioneering explorations, the reader may find the near absence of real-world data puzzling in a volume that aspires to be "a useful guide for empirical enquiry". To be sure, innovative working hypotheses lure the economist into an exciting research environment: cultural group selection fits human evolution better than rational choice based explanations (Joseph Henrich, "Cultural group selection, coevolutionary processes and largescale cooperation", 2004); an evolutionary environment is ideally suited to bring to light collaborative/defective patterns of human behaviour (Theodore C. Bergstrom, "Evolution of social behaviour", 2002; Samuel Bowles and Herbert Gintis, "Can self-interest explain cooperation?", 2005). However, game theory exercises, laboratory and thought experiments, plus stories of mice cooperation in haystack models, instructive though they may be, serve poorly as a practical reference to the way economies (may) function.

The two papers that are exceptions to this pattern raise questions of their own. In the first, Henrich, et al. ("In search of homo economicus", 2001) report the results of field experiments in 15 small-scale societies (i.e., foraging, nomadic herding, horticulturalist, and sedentary agriculturalist groups). Their study targets patterns of cooperation, 
reciprocity, or punishment to investigate the relevance of the canonical model of monetary-payoff-maximizing actors. The contrast between the case of primeval man's societies and modern behaviour seems justifiable on evolutionary grounds alone as long as both society and population are perceived as a collection of atomistic individuals. Dispensing with the canonical model altogether, to which the common thread of volume contributions in fact leads, would normally invite reflections of a different nature, for example on the cultural or historical significance of the sample and hence on the possibility of generalizing their findings. The second exception (J. W. Stoelhorst, "The naturalist view of universal Darwinism", 2007) looks through evolutionary lenses at the case of Intel's impressive advance to world dominance and concludes that selection in the marketplace operates in a similar manner as in biology. From this analysis, we learn that differential success is primarily a result of competition for resources rather than reproductive behaviour, one contending point the author wants to clarify, but remain unsure about the value of substituting the evolutionary mindset for good old competitive analysis in the first place.

Part three moves one step further from the use of analogy and metaphor and looks for an economic theory proper based on ontological communalities between social and biological evolution. The core Darwinian concepts of variation, inheritance, and selection apply to a very broad class of phenomena in the social realm, even though the selection criteria and mechanisms have nothing to do with biological survival and growth (Richard Nelson, "Evolutionary social science and universal Darwinism", 2006). The economist is instead challenged to identify preferences and values that are operative in social environments such as technology, business, and science.

A series of three papers written by Geoffrey M. Hodgson and Thorbjørn Knudsen ("Why we need a generalized Darwinism, and why generalized Darwinism is not enough", 2006; "The nature and units of social selection", 2006; "Information, complexity, and generative replication", 2008) proposes a virtually complete account of generative selection in the social domain. At a general level, its lesson is that appropriating Darwinian thought as a universal way of theorizing should not distract us from seeing that the ontologies of the human social world and biological structures are different. Accordingly, the 
model attempts to identify replicators and interactors that are relevant 'genotypes' and 'phenotypes' for socio-economic and cultural evolution.

The logic of social generative selection is founded on four "definitional features". Firstly, causality gets an evolutionary meaning on the premise that, citing David Hull, "interactions cause replication to be differential". A genotype or replicator is associated with a potential for differentiation at multiple levels of social interaction. It is for this reason that the selection process must be understood in terms of "corresponding pairs of replicators and interactors" which hold the key to understanding the observed behaviour. Secondly, the replicator should in its own capacity ensure copying fidelity among the social units of selection. Thirdly, the selective pressure is triggered by a transfer of generative information between interactors, like firms and institutions, and replicators, which act as "stores of social dispositions, rules and knowledge". A fourth and final feature is summed up by the conditional generative mechanism, a material entity which is required in order to "turn input signals from an environment into developmental instructions". It is thus possible to analyse the objects of our study as full-fledged "generative replicators", like habits and routines, that satisfy all four criteria, or as only "emergent expressions", like ideas, that fall short of developing a reproductive capability of their own.

Part two opposes the historical and nomological modes of evolutionary explanation, in contrast to the emphasis on common ground in parts one and three. On one side, Joseph Fracchia and R. C. Lewontin ("Does culture evolve?", 1999) are sceptical that "substituting the metaphor of evolution for history" may be of any use and think of it rather as the malign consequence of "the grand twentieth-century movement to scientize all aspects of the study of society". They disentangle natural selection explanations from cultural alternatives with possibly similar implications by analysing the restrictiveness of the contingent pattern of differential reproduction, which varies from "very strong constraints on which states may succeed each other" in evolutionary contexts to "purely random differential survival" in historical frames. The copying process may actually unfold in such unpredictable patterns that causation becomes impossible to discern. Two other complementary studies (Dan Sperber, "An objection to the memetic approach to culture", 2000; John S. Wilkins, "The appearance of Lamarckism in the evolution of culture", 2001) reinforce the point that a 
sensible distinction between the social actor and the biological individual rests on cultural attributions and learning.

On the other side, evolution is viewed as a lawful process of selection and adaptation, with in-built directionality and developmental stages. "We must search for a causal explanation", argue Geoffrey M. Hodgson and Thorbjørn Knudsen ("Dismantling Lamarckism", 2006), and natural selection is "the only possible" one. They and other contributing authors (e.g., Jack J. Vromen) find no evolutionary role for accidents of evolution. The selective process leads only to novelty; residual developmental errors are expurgated of "useless and injurious characteristics" which may prove detrimental to the potential to increase complexity.

The nature of the debate in part two returns us to the introductory text that serves to introduce Darwinism in the guise of a "middle-range theory" for reorienting economics towards the social realm. Much of that debate is inspired by Darwin himself who "hinted that his ideas may apply to other evolving systems, including language and social institutions" (p. xv). But it is probably safest to argue that he left the issue unsettled. For scholars who emphasize the historical nature of evolution, Darwin well understood that the mechanism of natural selection in fact applies poorly to the causes of social change (Gould $2007,547)$. A rereading of primary sources can conflate the controversial nature of the originator's idea. In 1859, Darwin was "convinced that Natural Selection has been the main but not exclusive means of modifications" (Darwin 1859, 6). Is this a cautious remark, mindful of other possible explanations, or is it just a marginal note, being the very last sentence of its prefatory text? In Darwin's 1882 The descent of man, after six revised editions of his Origin, carefully crafted phrases validating the universal character of selection, such as "When a poor man becomes moderately rich, his children enter trades or professions in which there is struggle enough, so that the able in body and mind succeed best" (Darwin 1882, 135), continue to conflict with ambiguous assertions about man's social and material progress that is made possible "due to his power of speaking and handing down his acquired knowledge" (Darwin 1882, 79).

Hodgson's introduction cautiously eschews appropriating evolutionary theory in the blunt way that ideas from physics were previously imported, giving birth to neoclassical economics. The book nevertheless falls short of convincingly substantiating its claim that 
Darwinian thought be construed as supportive of both interaction and communality theories. As has been suggested by some contributors to this very book, doubts persist as to the pivotal role causal explanation supposedly plays in providing a realistic view of the social world. It may just prove too elusive to pin down in a meaningful manner why things occur the way they do.

\section{REFERENCES}

Darwin, Charles. 1859. On the origin of species by means of natural selection, or the preservation of favoured races in the struggle for life. London: John Murray.

Darwin, Charles. 1882. The descent of man and selection in relation to sex, 2nd edition. London: John Murray.

Gould, Stephen Jay. 2007. The richness of life: a Stephen Jay Gould reader, eds. Paul McGarr, and Steven Rose. London: Vintage.

Valentin Cojanu is professor of international economics and business at the Bucharest Academy of Economic Studies (Romania), and editor of the Journal of Philosophical Economics.

Contact e-mail: <cojanu@ase.ro> 